\title{
The effects of radicular dentine treated with double antibiotic paste and ethylenediaminetetraacetic acid on the attachment and proliferation of dental pulp stem cells
}

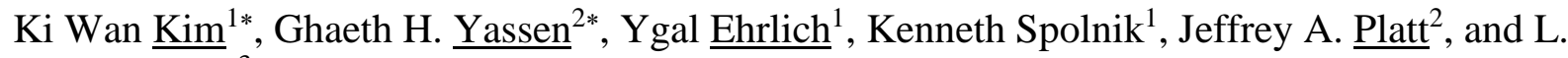
Jack Windsor ${ }^{3}$

${ }^{1}$ Department of Endodontics, Indiana University School of Dentistry, Indianapolis, IN, USA

${ }^{2}$ Department of Restorative Dentistry, Division of Dental Biomaterials, Indiana University School of Dentistry, Indianapolis, IN, USA

${ }^{3}$ Department of Oral Biology, Indiana University School of Dentistry, Indianapolis, IN, USA

* These authors contributed equally to this work.

Running title: Attachment of pulp stem cells to treated dentine

Keywords: Dental pulp stem cells, double antibiotic paste, endodontic regeneration, ethylenediaminetetraacetic acid, and radicular dentine.

\section{Conflict of interest}

The authors deny any conflicts of interest related to this study.

Correspondence:

L. Jack Windsor, Ph.D.

Department of Oral Biology, DS 271

Indiana University School of Dentistry,

1121 W. Michigan St.,

Indianapolis, IN 46202, USA

Tel: +1-317-274-1448; fax: +1-317-278-1411.

E-mail address: ljwindso@iu.edu

This is the author's manuscript of the article published in final edited form as:

Kim, K. W., Yassen, G. H., Ehrlich, Y., Spolnik, K., Platt, J. A., \& Windsor, L. J. (2015). The effects of radicular dentine treated with double antibiotic paste and ethylenediaminetetraacetic acid on the attachment and proliferation of dental pulp stem cells. Dental Traumatology, 31(5), 374-379. http://doi.org/10.1111/edt.12181 


\begin{abstract}
Aim: This study explored the effects of dentine treated with two concentrations of double antibiotic paste (DAP) and ethylenediaminetetraacetic acid (EDTA) on the attachment and proliferation of dental pulp stem cells (DPSCs).
\end{abstract}

Materials and Methods: Radicular dentine samples were prepared with identical dimensions and randomized into six groups $(n=4)$. Four groups were treated with double antibiotic paste (DAP) at concentrations of $500 \mathrm{mg} / \mathrm{mL}$ or $1 \mathrm{mg} / \mathrm{mL}$ with or without EDTA. The other two groups were treated with EDTA only or received no treatment. DPSCs were seeded on each dentine sample (10,000 cells per sample). Lactate dehydrogenase activity assays were used to calculate the attached DPSCs after one day of incubation. Water soluble tetrazolium assays were performed to investigate DPSCs proliferation on the treated dentine samples after three additional days of incubation. Two-way ANOVA followed by Tukey-Kramer tests were used for statistical analyses $(\alpha=0.05)$.

Results: Dentine treated with 1 or $500 \mathrm{mg} / \mathrm{mL}$ of DAP followed by EDTA caused significant increases in DPSCs attachment compared to the dentine treated with the DAP alone. The 500 $\mathrm{mg} / \mathrm{mL}$ of DAP with or without EDTA caused significant reductions in DPSCs proliferation. However, the treatment of dentine with $1 \mathrm{mg} / \mathrm{mL}$ of DAP did not have significant negative effects on DPSCs proliferation regardless of the use of EDTA.

Conclusion: The use of $1 \mathrm{mg} / \mathrm{mL}$ of DAP followed by 10 minutes irrigation with EDTA in endodontic regeneration procedure may have no negative effects on the attachment and proliferation of DPSCs. 


\section{Introduction}

Traumatic dental injuries and developmental dental anomalies are the main etiological factors of immature permanent teeth with pulpal necrosis (1). Regenerative endodontics (pulp revascularization) has been proposed to induce root development and to improve various clinical outcomes compared to other traditional treatments such as calcium hydroxide apexification and artificial apical barrier technique using mineral trioxide aggregate $(2,3)$.

The first essential step in endodontic regeneration therapy is to disinfect the root canal with intensive chemical challenge through irrigation with sodium hypocholrite and application of intracanal medicament for 1-4 weeks (4). The most commonly used intracanal medicaments during endodontic regeneration procedure are calcium hydroxide $(5,6)$ and triple antibiotic paste (TAP) $(7,8)$, which is a mixture of ciprofloxacin, metronidazol and minocycline. However, the presence of minocycline in TAP has been associated with tooth discoloration $(8,9)$. A double antibiotic paste devoid of minocycline (ciprofloxacin/metronidazole) was found to have comparable antibacterial effects against endodontic pathogens (10) and has been successfully used in endodontic regeneration (11). The second essential step in endodontic regeneration therapy is to optimize the biological environment inside the root canal for regeneration by root canal irrigation with EDTA (12) and induction of bleeding to create natural scaffold and provide enough cells inside the root canal $(4,13)$.

To optimize endodontic regeneration therapy, cells inside the root canal must be able to attach and proliferate on dentine surfaces $(14,15)$ as well as differentiate into odontoblast-like cells (16). Recent in vitro studies found that the clinically used concentrations of various antibiotic medicaments such as TAP and DAP had direct toxic effects on stem cells from apical papillae (SCAP) (17) and pulp fibroblasts (18). Therefore, the use of lower concentrations of 
TAP and DAP (0.1-1 mg/mL) have been recommended to avoid the cytotoxic effects of these medicaments $(4,17)$. On the other hand, EDTA has been proposed to promote cell survival during endodontic regeneration (12) due to its ability to demineralize superficial dentine (19), expose dentine organic matrix (20), improve dental pulp stem cells (DPSCs) adhesion (21) and release dentine endogenous growth factors (22). No previous studies have explored the ability of EDTA to modify the attachment and proliferation of stem cells on dentine treated with an intracanal antibiotic medicament. The aim of this study was to investigate the effects of dentine treated with two concentrations of DAP with or without EDTA irrigation on the attachment and proliferation of DPSCs.

\section{Materials and methods}

\section{Tooth selection and dentine sample preparation}

Intact single-rooted human teeth were selected after obtaining Indiana University Institutional Review Board approval (IRB number: 1212010183). The teeth were stored at $4{ }^{\circ} \mathrm{C}$ in $0.1 \%$ thymol solution and used within 6 months after extraction. Twenty four dentine slabs (4 mm width $\times 4$ mm length $\times 1 \mathrm{~mm}$ thickness) were obtained from the cervical half of each root using a low-speed diamond saw (Isomet, Buehler, Lake Bluff, IL, USA) under running distilled water. The outer non-pulpal surface of each specimen was flattened using an automatic polishing unit (Struers, Cleveland, PA, USA) with 500 grit paper (Struers). The pulpal side of each dentine slab was polished using a polishing unit with 1200-, 2400- and 4000-grit papers (Struers) and finally using a diamond polishing spray $(1 \mu \mathrm{m}$; Struers). Polished dentine slabs were sonicated for three minutes in neutral detergent solution and rinsed for an additional 3 min with de-ionized water. All the samples were examined under light microscopy and any dentine slab with cracks was discarded and replaced. Finally, dentine slabs were washed with sterile water, placed 
individually in Whirl-pak bags (Sigma-Aldrich, St Louis, MO, USA) containing a moist cotton pellet, gas sterilized with ethylene oxide, and stored at $4{ }^{\circ} \mathrm{C}$ until used.

\section{Dentine treatment procedure}

The dentine slabs were removed from $4{ }^{\circ} \mathrm{C}$ and washed with sterile water for 2 min. Each dentine slab was then placed in a well of a 48-well plate (BD Falcon, San Jose, CA, USA) with the pulpal surface facing upward. Dentine slabs were randomized intro six groups ( $\mathrm{n}=4$ per group). The first and second experimental groups were treated with $400 \mu \mathrm{L}$ of a thin pasty consistency of DAP generated by mixing $500 \mathrm{mg}$ of equal portions metronidazole and ciprofloxacin (Champs Pharmacy, San Antonio, TX, USA) with $1 \mathrm{~mL}$ of sterile water. This 500 $\mathrm{mg} / \mathrm{mL}$ concentration of DAP was selected because it is the minimum amount of DAP required to create a pasty consistence that can be applied clinically into the root canal. The pulpal surface of the dentine slabs in the third and fourth groups were treated with $400 \mu \mathrm{L}$ of a watery consistency of DAP generated by mixing $50 \mathrm{mg}$ of equal portions metronidazole and ciprofloxacin with $50 \mathrm{~mL}$ of sterile water. This $1 \mathrm{mg} / \mathrm{mL}$ concentration of DAP was selected because it is the concentration of DAP suggested to be used during endodontic regeneration according to a recent in vitro study (15). The pulpal surface of the dentine slabs in the fifth and sixth groups were exposed to $400 \mu \mathrm{L}$ of sterile water. After that, all the dentine slabs were incubated for one week at $37^{\circ} \mathrm{C}$ with an approximately $100 \%$ relative humidity. The one week dentine treatment with DAP was selected because it is the shortest intracanal application time of medicaments recommended by the American Association of Endodontists (AAE) during endodontic regeneration procedure (23). After one week incubation, the DAP treated dentine slabs were rinsed with distilled water until there was no visible DAP. The pulpal surface of dentine slabs from groups one, four and six were then slowly irrigated with $20 \mathrm{~mL}$ of $17 \%$ 
EDTA (Henry Schein, Melville, NY, USA) for 10 min. The irrigation time of EDTA was selected based on a current clinical regeneration protocol (4). Finally, each dentine slab was rinsed with $500 \mu \mathrm{L}$ of phosphate buffered saline (PBS) and transferred into individual wells of a sterile non-treated low attachment 96-well plate (Thermo Scientific, Waltham, MA, USA) with the treated side of each dentine slab facing upward.

\section{DPSCs culture and seeding on dentine}

DPSCs (Cook General BioTechnology, Indianapolis, IN) were used in this study. The protocol used to harvest these cells has been previously described (24). Furthermore, the ability of these cells to express various mesenchymal cell surface markers and to differentiate into various tissues in the appropriate differentiation medium has been established in previous reports $(24,25)$. DPSCs were cultured in low glucose (1 g/L) Dulbecco’s Modified Eagle’s Media (DMEM) supplemented with 10\% fetal bovine serum (FBS), 4 mM L-glutamine, 2.5 $\mathrm{g} / \mathrm{mL}$ fungizone, $100 \mathrm{unit} / \mathrm{ml}$ penicillin, and $50 \mathrm{~g} / \mathrm{mL}$ gentamicin for 7 days at $37^{\circ} \mathrm{C}$, and $5 \%$ $\mathrm{CO}_{2}$. Sub-confluent cells between passages 3 and 5 were utilized in this study.

DPSCs were seeded on the treated pulpal surface of each dentine slab $(10,000$ cells/sample). After 24 hours attachment period, the media containing the unattached cells were collected and the cells were lysed utilizing Lactate Dehydrogenase Activity (LDH) assays and used to determine the amount of unattached and attached DPSCs. Each dentine sample was then washed with $100 \mu \mathrm{L}$ of serum-plus DMEM and the attached DPSCs on each dentine slab received $200 \mu \mathrm{L}$ of DMEM containing 10\% FBS and incubated for an additional three days. After a three day culture period, water soluble tetrazolium salts (WST-1) assays were performed to determine DPSCs proliferation on the treated dentine samples. 


\section{LDH assays}

LDH permeability assays were utilized to measure the release of lactate dehydrogenase from unattached DPSCs after lysis in a 96 well plate following 24 hours for attachment. A 100 $\mu \mathrm{l}$ mix of reconstituted LDH prepared according to the manufacturer's protocol (Roche Applied Science, Indianapolis, IN, USA) was added to each sample and incubated for $30 \mathrm{~min}$ at $23^{\circ} \mathrm{C}$ (room temperature). The absorbance was measured at $490 \mathrm{~nm}$ in a microplate reader (Titertek, Multiskan MCC, Flow Laboratories, McLean, VA, USA). The culture media from four dentine specimens without cells were used as low controls. Maximum LDH release from 10,000 cells was generated by adding10 $\mu \mathrm{l}$ of the lysis solution provided by the manufacturer for 30 min (high control). The percentages of unattached DPSCs after various dentine treatments were calculated relative to total amount of cells (DPSCs with no dentine specimens) according to the following equation: Unattached DPSCs $(\%)=$ (experimental absorbance value - low control absorbance value) / (high control absorbance value - low control absorbance value) $\times 100$. Finally, the percentage of attached cells after various treatments was calculated by subtracting the percentage of unattached cells from the percentage of total cells. The percentage of total cells (both attached and unattached) was considered 100\%.

\section{WST-1 assays}

WST-1 proliferation assays were used to measure the activity of mitochondrial dehydrogenase of the DPSCs attached to treated dentine surfaces. After three days of incubation, DPSCs on each dentine slab were washed with $2 \mathrm{~mL}$ of serum-free media and incubated with 10 $\mu$ l WST-1 (Roche Applied Science, Penzberg, Germany) and $100 \mu$ l serum-free DMEM for 2 hours in a humidified atmosphere at $37^{\circ} \mathrm{C}$ and $5 \% \mathrm{CO}_{2}$. After 2 hours, $100 \mu$ l of reaction mixture from each well (dentine slab) was transferred to a new 96-well plate and a spectrophotometer 
(Titertek) was used to measure the optical absorbance of each well at $450 \mathrm{~nm}$. The culture media from the four dentine specimens without cells were used as a low control. The maximum WST-1 signal from 10,000 cells was also determined (high control). The percentage of DPSCs proliferation on treated dentine samples in comparison to 10,000 cells was calculated according to the following equation: Proliferation of attached DPSCs $(\%)=$ (experimental absorbance value - low control absorbance value) / (high control absorbance value - low control absorbance value) $\times 100$.

\section{Statistical Analyses}

All data were checked for normality using the Shapiro-Wilk test and the normality assumption was satisfied. The effects of the DAP concentration and final irrigation with EDTA on the attachment and proliferation of DPSCs was examined using two-way ANOVA followed by Tukey-Kramer pairwise comparisons ( $\alpha=0.05)$. The high control groups (DPSCs with no dentine specimens) in both experiments were excluded from the statistical model and only used as reference groups to calculate the percentages of attachment and proliferation.

\section{Results}

For DPSCs attachment experiments, the interaction between DAP concentration and EDTA was significant $(\mathrm{p}=0.0006)$. Figure 1 shows that dentine treated with 1 or $500 \mathrm{mg} / \mathrm{mL}$ of DAP with no EDTA had significant reductions in the attachment of DPSCs compared to untreated dentine $(\mathrm{p}=0.0006$ and $\mathrm{p}=0.001$, respectively). However, no significant differences was found in the attachment of DPSCs between dentine treated with 1 and $500 \mathrm{mg} / \mathrm{mL}$ of DAP without EDTA (p>0.05). Dentine treated with $1 \mathrm{mg} / \mathrm{mL}$ of DAP with no EDTA had significant reductions in the attachment of DPSCs compared to dentine treated with $1 \mathrm{mg} / \mathrm{mL}$ of DAP followed by EDTA ( $\mathrm{p}=0.008$ ). Additionally, dentine treatment with $500 \mathrm{mg} / \mathrm{mL}$ of DAP without 
EDTA caused significant reductions in the attachment of DPSCs compared to dentine treated with $500 \mathrm{mg} / \mathrm{mL}$ of DAP followed by EDTA ( $\mathrm{p}=0.005$ ). However, no significant difference was found in the attachment of DPSCs between untreated dentine and dentine treated with EDTA only ( $p>0.05)$. Furthermore, no significant differences were found in the attachment of DPSCs between dentine treated with EDTA and that treated with $1 \mathrm{or} 500 \mathrm{mg} / \mathrm{mL}$ of DAP followed by EDTA (all p>0.05).

For DPSCs proliferation experiments, the interaction between DAP concentration and EDTA was not significant ( $\mathrm{p}=0.93$ ). Furthermore, the overall EDTA effect was not significant $(\mathrm{p}=0.15)$. Figure 2 shows that the treatment of dentine with $500 \mathrm{mg} / \mathrm{ml}$ of DAP with no EDTA caused significant reductions in the proliferation of DPSCs compared to dentine treated with 1 $\mathrm{mg} / \mathrm{ml}$ of DAP without EDTA and untreated dentine ( $<<0.0001)$. However, no significant difference was detected between dentin treated with $1 \mathrm{mg} / \mathrm{ml}$ of DAP without EDTA and untreated dentine ( $>>0.05$ ). The treatment of dentine with $500 \mathrm{mg} / \mathrm{ml}$ of DAP followed by EDTA caused significant reductions in the proliferation of DPSCs compared to dentine treated with 1 $\mathrm{mg} / \mathrm{ml}$ of DAP followed by EDTA ( $\mathrm{p}>0.027)$ and dentine treated with EDTA only ( $\mathrm{p}=0.002)$. However, no significant difference was detected between dentin treated with $1 \mathrm{mg} / \mathrm{ml}$ of DAP followed by EDTA and that treated with EDTA only (p>0.05). Furthermore, no significant differences were detected between dentine groups treated with DAP followed by EDTA compared to dentine groups treated with the same concentration of DAP with no EDTA $(\mathrm{p}>0.05)$.

\section{Discussion}

To create new dentine during endodontic regeneration therapy, DPSCs or other stem cells must be able to attach to the treated root canal dentine and subsequently proliferate and 
differentiate $(14,26)$. Previous studies have explored the effects of various irrigation solutions on the attachment of DPSCs to radicular dentine $(14,21,26,27)$. However, the present study is the first attempt to investigate the effects of dentine treated with intracanal medicament followed by EDTA on the attachment and proliferation of DPSCs.

This study showed that the treatments of 1 or $500 \mathrm{mg} / \mathrm{mL}$ DAP without EDTA caused significant reductions in DPSCs attachment to dentine. This could be explained by residual cytotoxic effects of DAP or the changes in dentine surface topography that may compromise the attachment of DPSCs. A previous study has also shown that DAP concentrations ranging from 1$100 \mathrm{mg} / \mathrm{mL}$ had detrimental direct cytotoxic effects on SCAP (17) and pulp fibroblasts (18). Furthermore, one week application of DAP $(\mathrm{pH}=3.4)$ was suggested to cause significant demineralization of the dentine surface (28). The current study showed that dentine treated with 1 or $500 \mathrm{mg} / \mathrm{mL}$ of DAP followed by 10 minute irrigation with EDTA caused significant improvements in DPSCs attachment compared to dentine treated with DAP without EDTA. This could be attributed to the ability of EDTA to wash out the residual DAP present in dentine and to expose various dentine matrix components and growth factors such as transforming growth factor- $\beta$, fibroblast growth factor 2 , and bone morphogenetic protein $2(22,29)$.

In the current study, no significant differences were found in the attachment of DPSCs between untreated dentine and dentine irrigated with EDTA. This finding is consistent with a previous study that found no significant differences in the attachment of DPSCs to radicular dentine regardless of the use of EDTA (14). However, other studies have found that irrigation of dentine with EDTA caused significant improvement in the attachment of DPSCs (21) and pulp fibroblasts (27). It is noteworthy to mention that previous studies $(14,21,27)$ investigated the ability of EDTA to improve DPSCs and pulp fibroblast attachment to dentine used relatively 
short EDTA irrigation times (15-60 seconds) compared to the current study (10 minutes).

However, 10 minutes irrigation with EDTA was selected in this study based on a current clinical recommendation of endodontic regeneration treatment (4). The long EDTA irrigation time may be helpful in washing out the remaining intracanal medicaments and improve DPSCs attachment within the context of the endodontic regeneration clinical protocol. However, dentine irrigation with EDTA for long periods without pervious application of intracanal medicament may not be beneficial to the attachment of DPSCs.

This study showed that dentine treated with $500 \mathrm{mg} / \mathrm{mL}$ of DAP had negative effects on the proliferation of DPSCs even after 10 minute irrigation with EDTA. This generally agrees with a recent study that suggested that dentine treatment with a pasty concentration of DAP $(1000 \mathrm{mg} / \mathrm{mL})$ had deleterious effects on SCAP seeded in a synthetic scaffold within the root canal lumen (15). The presence of a continuous residual cytotoxic effects from dentine treated with DAP even after irrigation with EDTA may negatively affect DPSCs proliferation. A recent study suggested that radicular dentine treated with $1 \mathrm{mg} / \mathrm{mL}$ or $1000 \mathrm{mg} / \mathrm{mL}$ of DAP for two weeks exerted residual antibacterial effects up to one month after DAP removal (30). On the other hand, the current study showed that dentine treated with $1 \mathrm{mg} / \mathrm{mL}$ DAP significantly improved DPSCs proliferation compared to the use of $500 \mathrm{mg} / \mathrm{mL}$ of DAP regardless of the use of EDTA. This agrees with a recent study that reported that dentine treated with $1 \mathrm{mg} / \mathrm{mL}$ of DAP had no cytotoxic effects on SCAP seeded in a synthetic scaffold within the root canal (15).

Current AAE recommendation suggest the use of $0.1 \mathrm{mg} / \mathrm{mL}$ of DAP or TAP in endodontic regeneration (23) as this relatively low concentration has no cytotoxic effects on SCAP (17) and was proposed to have significant antibacterial effects on Enterococcus faecalis and Porphyromonas gingivalis newly formed biofilms $(10,30)$. On the other hand, a recent study 
showed that the use of $1 \mathrm{mg} / \mathrm{mL}$ of DAP exert significantly better antibacterial effect against established bacterial biofilm compared to the use of $0.1 \mathrm{mg} / \mathrm{mL}$ of DAP (31). Therefore, 1 $\mathrm{mg} / \mathrm{mL}$ of DAP may be an effective antibacterial medicament during endodontic regeneration without negatively affecting DPSCs proliferation on radicular dentine. However, $1 \mathrm{mg} / \mathrm{mL}$ of DAP is in a liquid form and some sort of vehicle should be considered to produce a clinically applicable intracanal dressing.

In this study, the use of 1 or $500 \mathrm{mg} / \mathrm{mL}$ DAP with EDTA did not significantly improve the DPSCs proliferation on radicular dentine compared to dentin treated with EDTA alone. However, a clear trend of improvement in DPSCs proliferation was noticed among all dentine groups treated with DAP and EDTA compared to groups treated with the same concentration of DAP without EDTA. This indicates that dentine irrigation with EDTA after treatment with DAP might reduce the deleterious effects of DAP on the proliferation of DPSCs. The aforementioned observation might help explain the acceptable clinical outcomes of the majority of endodontic regeneration cases reported in the literature despite the use of cytotoxic concentrations of intracanal antibiotic medicaments. One limitation of the current study is the relatively small sample size; a larger sample size per group may have shown more significant results. However, two-way ANOVA was used for statistical analyses to increase the statistical power and minimize the total sample size required for the study.

\section{Conclusions}

Our study demonstrated that dentine treated with 1 or $500 \mathrm{mg} / \mathrm{mL}$ of DAP followed by 10 minute irrigation with EDTA can significantly improve the attachment of DPSCs compared to dentine treated with DAP without EDTA. Furthermore, the treatment of dentine with $1 \mathrm{mg} / \mathrm{mL}$ of DAP for one week did not have significant negative effects on the DPSCs proliferation 
regardless of the use of EDTA. An endodontic regeneration protocol that includes the use of 1

$\mathrm{mg} / \mathrm{mL}$ of DAP followed by 10 minutes irrigation with EDTA may be recommended to avoid any negative effects on the attachment and proliferation of DPSCs.

\section{References}

1. Diogenes A, Henry MA, Teixeira FB, Hargreaves KM. An update on clinical regenerative endodontics. Endod Top. 2013;28:2-23.

2. Bose $R$, Nummikoski $P$, Hargreaves $K$. A retrospective evaluation of radiographic outcomes in immature teeth with necrotic root canal systems treated with regenerative endodontic procedures. J Endod. 2009;35:1343-9.

3. Jeeruphan T, Jantarat J, Yanpiset K, Suwannapan L, Khewsawai P, Hargreaves KM. Mahidol study 1: comparison of radiographic and survival outcomes of immature teeth treated with either regenerative endodontic or apexification methods: a retrospective study. J Endod. 2012;38:1330-6.

4. Diogenes AR, Ruparel NB, Teixeira FB, Hargreaves KM. Translational science in disinfection for regenerative endodontics. J Endod. 2014;40:S52-7.

5. Chueh LH, Ho YC, Kuo TC, Lai WH, Chen YH, Chiang CP. Regenerative endodontic treatment for necrotic immature permanent teeth. J Endod. 2009;35:160-4.

6. Chen MY, Chen KL, Chen CA, Tayebaty F, Rosenberg PA, Lin LM. Responses of immature permanent teeth with infected necrotic pulp tissue and apical periodontitis/abscess to revascularization procedures. Int Endod J. 2012;45:294-305.

7. Nagy MM, Tawfik HE, Hashem AA, Abu-Seida AM. Regenerative potential of immature permanent teeth with necrotic pulps after different regenerative protocols. J Endod. 2014;40:192-8.

8. Nagata JY, Gomes BP, Rocha Lima TF, Murakami LS, de Faria DE, Campos GR, et al. Traumatized immature teeth treated with 2 protocols of pulp revascularization. J Endod. 2014;40:606-12.

9. $\quad \operatorname{Kim} J H, K i m$ Y, Shin SJ, Park JW, Jung IY. Tooth discoloration of immature permanent incisor associated with triple antibiotic therapy: a case report. J Endod. 2010;36:1086-91.

10. Sabrah AH, Yassen GH, Gregory RL. Effectiveness of antibiotic medicaments against biofilm formation of Enterococcus faecalis and Porphyromonas gingivalis. J Endod. 2013;39:1385-9.

11. Iwaya SI, Ikawa M, Kubota M. Revascularization of an immature permanent tooth with apical periodontitis and sinus tract. Dent Traumatol. 2001;17:185-7.

12. Trevino EG, Patwardhan AN, Henry MA, Perry G, Dybdal-Hargreaves N, Hargreaves KM, et al. Effect of irrigants on the survival of human stem cells of the apical papilla in a platelet-rich plasma scaffold in human root tips. J Endod. 2011;37:1109-15.

13. Lovelace TW, Henry MA, Hargreaves KM, Diogenes A. Evaluation of the delivery of mesenchymal stem cells into the root canal space of necrotic immature teeth after clinical regenerative endodontic procedure. J Endod. 2011;37:133-8.

14. Ring KC, Murray PE, Namerow KN, Kuttler S, Garcia-Godoy F. The comparison of the effect of endodontic irrigation on cell adherence to root canal dentin. J Endod. 2008;34:1474-9. 
15. Althumairy RI, Teixeira FB, Diogenes A. Effect of dentin conditioning with intracanal medicaments on survival of stem cells of apical papilla. J Endod. 2014;40:521-5.

16. Huang GT, Yamaza T, Shea LD, Djouad F, Kuhn NZ, Tuan RS, et al. Stem/progenitor cellmediated de novo regeneration of dental pulp with newly deposited continuous layer of dentin in an in vivo model. Tissue Eng Part A. 2010;16:605-15.

17. Ruparel NB, Teixeira FB, Ferraz CC, Diogenes A. Direct effect of intracanal medicaments on survival of stem cells of the apical papilla. J Endod. 2012;38:1372-5.

18. Labban N, Yassen GH, Windsor $U$, Platt JA. The direct cytotoxic effects of medicaments used in endodontic regeneration on human dental pulp cells. Dent Traumatol. 2014;30:429-34.

19. Zhang K, Kim YK, Cadenaro M, Bryan TE, Sidow SJ, Loushine RJ, et al. Effects of different exposure times and concentrations of sodium hypochlorite/ethylenediaminetetraacetic acid on the structural integrity of mineralized dentin. J Endod. 2010;36:105-9.

20. Galler KM, D'Souza RN, Federlin M, Cavender AC, Hartgerink JD, Hecker S, et al. Dentin conditioning codetermines cell fate in regenerative endodontics. J Endod. 2011;37:1536-41.

21. Pang NS, Lee SJ, Kim E, Shin DM, Cho SW, Park W, et al. Effect of EDTA on attachment and differentiation of dental pulp stem cells. J Endod. 2014;40:811-7.

22. Begue-Kirn C, Smith AJ, Ruch JV, Wozney JM, Purchio A, Hartmann D, et al. Effects of dentin proteins, transforming growth factor beta 1 (TGF beta 1 ) and bone morphogenetic protein 2 (BMP2) on the differentiation of odontoblast in vitro. Int J Dev Biol. 1992;36:491-503.

23. American Association of Endodontists. Considerations for Regenerative Procedures. Available at: http: www.aae.org/clinical-resources/regenerative-endodontics/considerations-forregenerative-procedures.aspx. Accessed August 12, 2014.

24. Perry BC, Zhou D, Wu X, Yang FC, Byers MA, Chu TM, et al. Collection, cryopreservation, and characterization of human dental pulp-derived mesenchymal stem cells for banking and clinical use. Tissue Eng Part C Methods. 2008;14:149-56.

25. Woods EJ, Perry BC, Hockema JJ, Larson L, Zhou D, Goebel WS. Optimized cryopreservation method for human dental pulp-derived stem cells and their tissues of origin for banking and clinical use. Cryobiology. 2009;59:150-7.

26. Huang GT, Sonoyama W, Chen J, Park SH. In vitro characterization of human dental pulp cells: various isolation methods and culturing environments. Cell Tissue Res. 2006;324:225-36.

27. Huang $X$, Zhang J, Huang $C$, Wang $Y$, Pei D. Effect of intracanal dentine wettability on human dental pulp cell attachment. Int Endod J. 2012;45:346-53.

28. Yassen GH, Chu TM, Eckert G, Platt JA. Effect of medicaments used in endodontic regeneration technique on the chemical structure of human immature radicular dentin: an in vitro study. J Endod. 2013;39:269-73.

29. Roberts-Clark DJ, Smith AJ. Angiogenic growth factors in human dentine matrix. Arch Oral Biol. 2000;45:1013-6.

30. Sabrah AH. Diluted antibiotics for treating traumatized immature teeth [Dissertation], Indiana University School of Dentistry; 2014.

31. Sabrah AH, Yassen GH, Liu WC, Goebel WS, Gregory RL, Platt JA. The effect of diluted triple and double antibiotic pastes on dental pulp stem cells and established Enterococcus faecalis biofilm. Clin Oral Investig. 2015. (In press) 
Figure 1. The percentages (mean + SE) of DPSCs attachment to radicular dentine evaluated by LDH assays after various dentine treatments with or without DAP and EDTA. Within each DAP treatment concentration, different upper-case letters indicate statistically significant differences between dentine treated with or without EDTA. Within each EDTA treatment condition, different lower-case letters indicate statistically significant differences between dentin treated with various concentration of DAP.

Figure 2. The percentages (mean + SE) of DPSCs proliferation on radicular dentine evaluated by WST-1 assays after various dentine treatments with or without DAP and EDTA. Within each DAP treatment concentration, different upper-case letters indicate statistically significant differences between dentine treated with or without EDTA. Within each EDTA treatment condition, different lower-case letters indicate statistically significant differences between dentin treated with various concentration of DAP. 


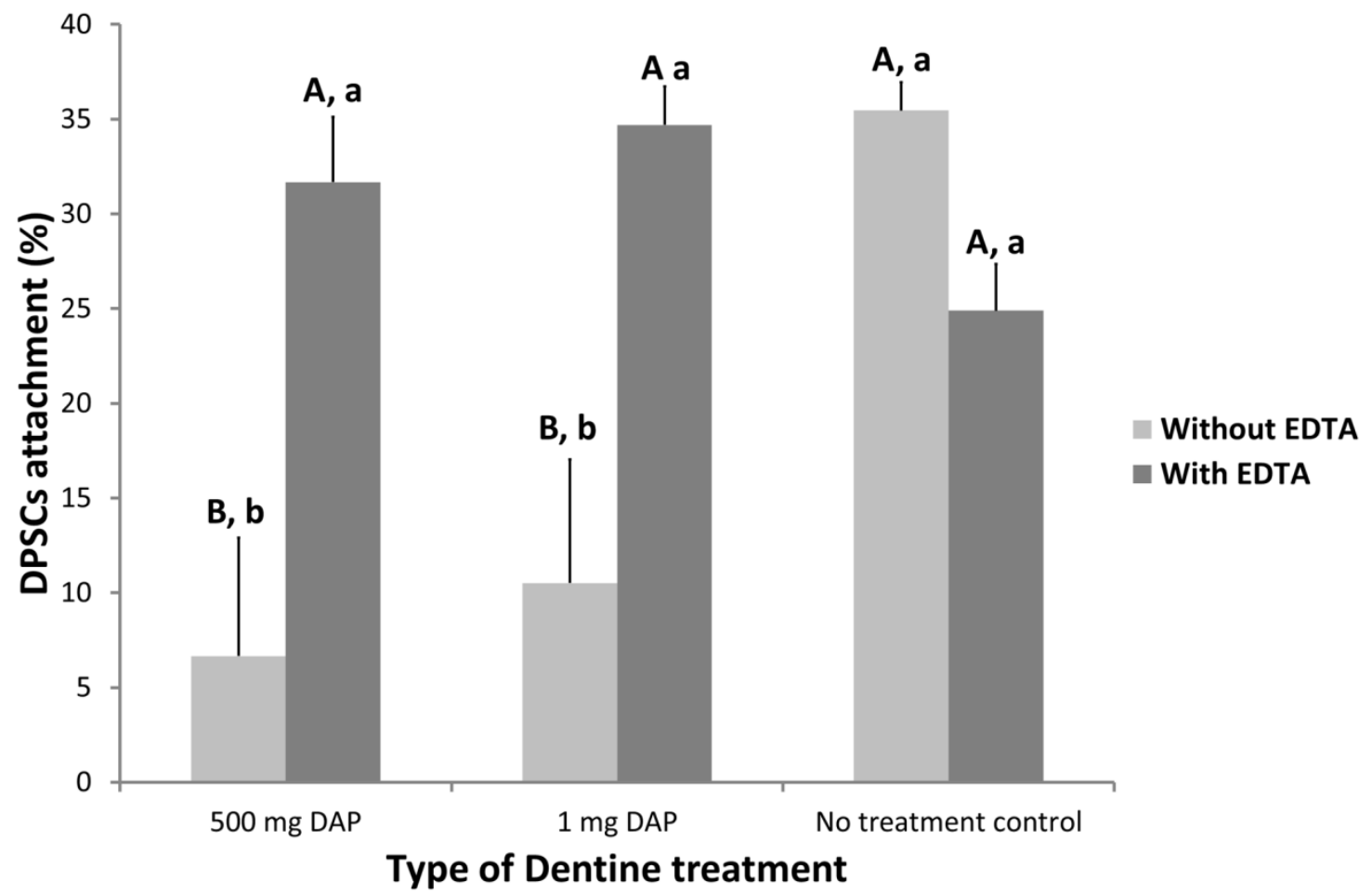

Figure 1 


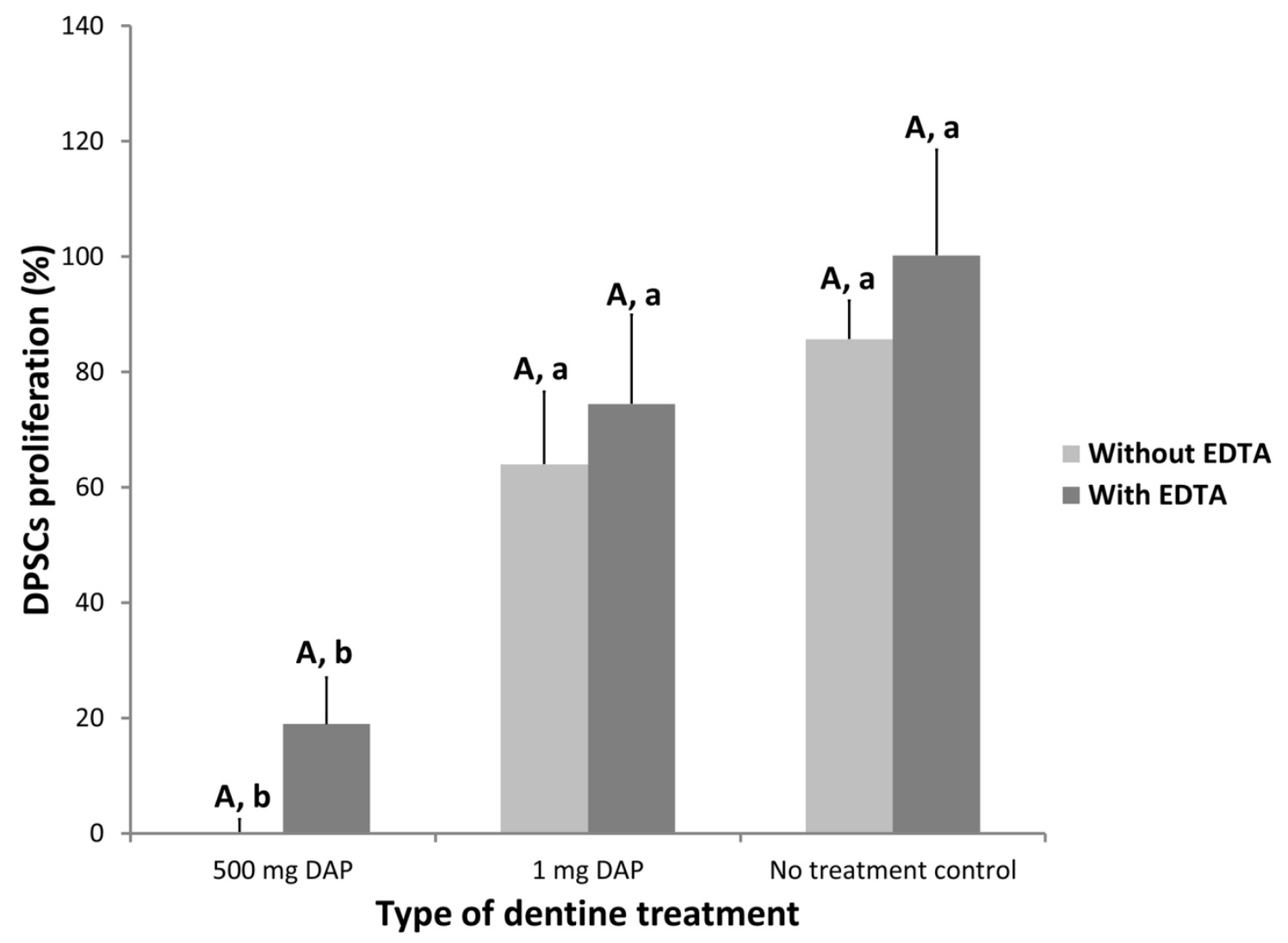

Figure 2 